\title{
Expansion of cat-ELCCA for the Discovery of Small Molecule Inhibitors of the Pre-let-7-Lin28 RNA-Protein Interaction
}

\author{
Daniel A. Lorenz, ${ }^{\dagger}$ Tanpreet Kaur, ${ }^{\ddagger}$ Samuel A. Kerk, ${ }^{\ddagger}$ Erin E. Gallagher, ${ }^{\ddagger}$ Jorge Sandoval, ${ }^{\dagger}$ \\ and Amanda L. Garner* ${ }^{*}, \ddagger$ (†)
}

${ }^{\dagger}$ Program in Chemical Biology and ${ }^{\ddagger}$ Department of Medicinal Chemistry, College of Pharmacy, University of Michigan, Ann Arbor, Michigan 48109, United States

\section{Supporting Information}

ABSTRACT: Dysregulation of microRNA (miRNA) expression has been linked to many human diseases; however, because of the challenges associated with RNA-targeted drug discovery, additional approaches are needed for probing miRNA biology. The emerging regulatory role of miRNA-binding proteins in miRNA maturation presents such an alternative strategy. Exploiting our laboratory's click chemistry-based high-throughput screening (HTS) technology, catalytic enzyme-linked click chemistry assay or cat-ELCCA, we have designed a modular method by which to discover new chemical tools for manipulating pre-miRNA-miRNA-binding protein interactions. Using the pre-let-7dLin28 interaction as proof-of-concept, the results presented demonstrate how HTS using cat-ELCCA can enable the discovery of small molecules targeting RNA-protein interactions.

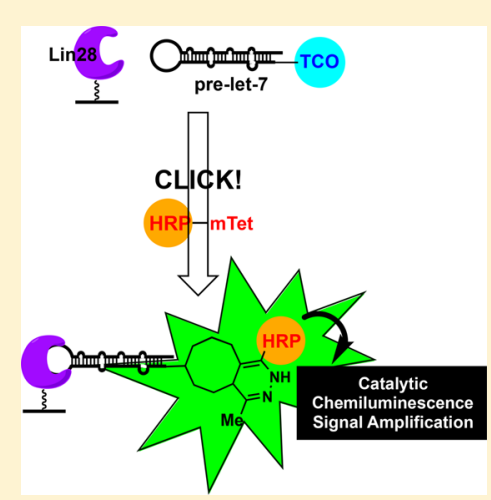

KEYWORDS: MicroRNA, RNA-binding proteins, high-throughput screening, chemical probes

$\mathrm{M}$ icroRNAs (miRNA or $\mathrm{miR}$ ) are small $\sim 21-23$ nucleotide noncoding RNAs that play a crucial role in downregulating the translation of select target genes. Because an individual miRNA can target up to hundreds of mRNAs (mRNA), alterations in miRNA expression have been linked to many human diseases. ${ }^{1}$ In cancer, global downregulation of tumor suppressor miRNAs (TS-miRs) is commonly observed and has been demonstrated to be a causative feature in tumorigenesis. $^{2-4}$ Loss can stem from genetic mutation or deletion, promoter methylation, or dysregulation of miRNA biogenesis. ${ }^{2}$ Of these mechanisms, alteration of global miRNA biogenesis is receiving increased attention due to recent findings demonstrating the critical role that miR-binding proteins (miR-BPs) play in the inhibition of this process, ultimately stimulating TS-miR degradation and cancer development. $^{5-8}$

The canonical biogenesis of a mature miRNA derives from two intermediate hairpin loops, nuclear pri-miRNA and cytosolic pre-miRNA, and is mediated by the RNase III enzymes, Drosha and Dicer, respectively. ${ }^{9}$ Only mature miRNAs function in gene silencing. ${ }^{9}$ Importantly, the hairpin loop motif of pri- and pre-miRNAs has been found to be a critical regulatory element serving as a docking site for miR-BPs that affect maturation. The most well-characterized is the let-7Lin 28 interaction, where Lin 28 protein functions as an inhibitor of let-7 maturation by binding to the hairpin loop of pri- and pre-let-7. ${ }^{10-12}$ Two isoforms of Lin28 exist in humans, Lin28A and Lin28B (collectively referred to as Lin28). ${ }^{12}$ Both interact similarly and use three RNA-binding domains to regulate let-7 maturation: an N-terminal cold shock domain and two CCHC zinc knuckle domains. ${ }^{13}$ The binding affinity $\left(K_{\mathrm{d}}\right)$ of full-length Lin28 for pre-let-7 is between $33-65 \mathrm{nM}$, and the zinc knuckle domains have been found to afford the selectivity of $\operatorname{Lin} 28$ for let-7 and contribute significantly to its binding affinity. ${ }^{14,15}$

The let-7 family plays an important role in cancer development and progression by downregulating cellular oncogenes including RAS and its mutant isoforms and Myc. ${ }^{16}$ Lin28 binding recruits terminal uridylyltransferases (TUTases), which polyuridylylate the $3^{\prime}$ terminus of pre-let-7 to inhibit Dicer processing and promote let-7 degradation. ${ }^{17}$ Loss of let-7 through this mechanism has been observed in at least $15 \%$ of all human cancers, including lung, breast, liver, esophageal, stomach, ovarian, prostate, and colon cancers, neuroblastoma, and chronic lymphocytic leukemia. ${ }^{3,4,12,18}$ Related, reduced let7 levels have been found to correlate with poor prognosis and decreased patient survival. ${ }^{18}$ Importantly, delivery of a let-7 mimic or knockdown of Lin28 has been shown to reduce tumor growth in vivo, ${ }^{19-23}$ indicating the potential for anticancer agents targeted at restoring physiological levels of this TS-miR.

Over the past few years, our laboratory has developed highthroughput screening (HTS) technology called catalytic enzyme-linked click chemistry assay, or cat-ELCCA. ${ }^{24-27}$ Key advantages of this approach for HTS include its increased

Special Issue: Med Chem Tech: Driving Drug Development

Received: March 14, 2018

Accepted: May 16, 2018

Published: May 16, 2018 
A

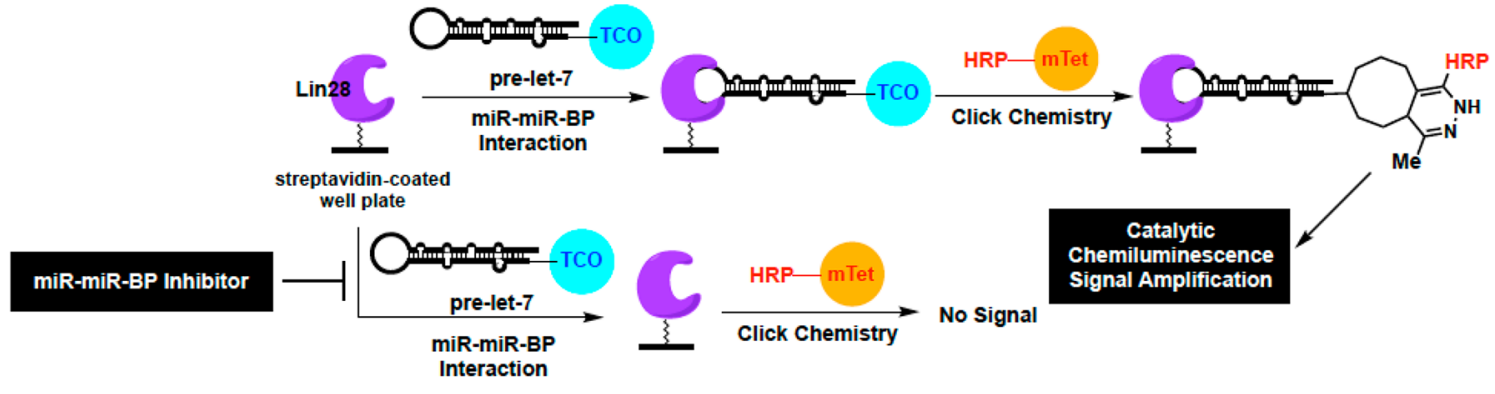

B

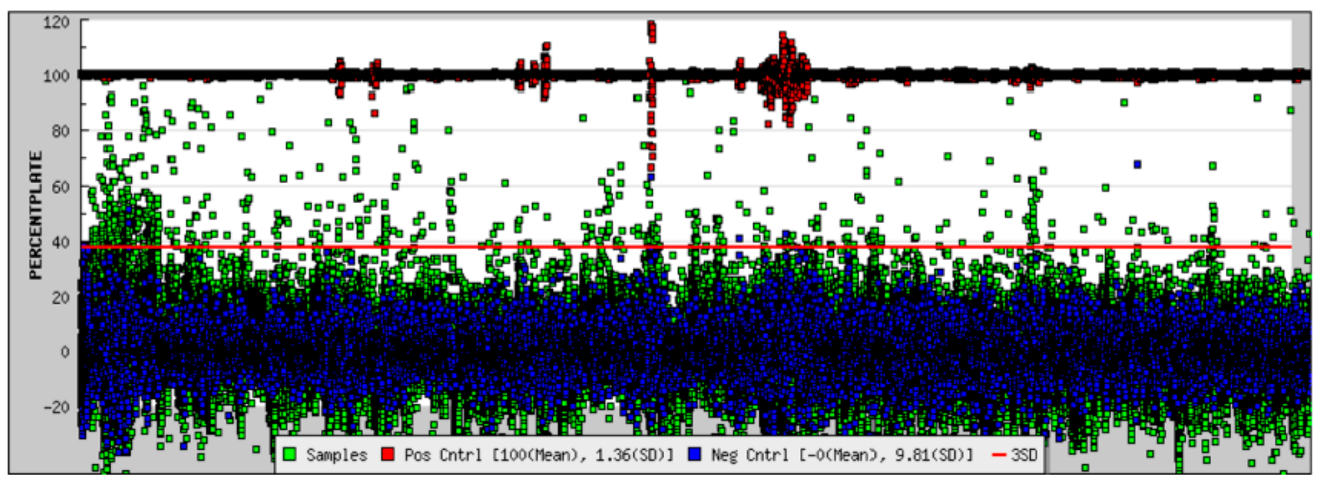

Figure 1. cat-ELCCA for the pre-let-7d-Lin28 miR-miR-BP interaction. (A) Assay scheme. (B) HTS campaign.

sensitivity due to catalytic signal amplification, robustness, and negligible compound interference in comparison to traditional fluorescence-based assays due to added washing steps. ${ }^{27,28}$ To date, we have applied cat-ELCCA for the discovery of premiRNA-selective small molecule probes ${ }^{29}$ and inhibitors of an acyltransferase $^{30}$ and protein-protein interactions (PPI). ${ }^{31}$ Herein, we describe further expansion of cat-ELCCA for the discovery of inhibitors of miR-miR-BP interactions, namely, the pre-let-7-Lin 28 interaction. Through these efforts, we have developed a robust screening platform for RNA-protein interactions and used this approach to discover a new chemotype capable of inhibiting a RNA-binding protein.

A scheme of cat-ELCCA for the pre-let-7-Lin28 interaction is shown in Figure 1A. In brief, drawing inspiration from PPI cat-ELCCA, ${ }^{31}$ murine Lin28A was first expressed as a $\mathrm{N}$ terminal HaloTag fusion protein, labeled with biotin, and immobilized into the wells of a streptavidin-coated microtiter plate. Contrary to our Dicer-mediated pre-miRNA maturation cat-ELCCA, $^{25,26,29}$ we chose to immobilize Lin28A, as preliminary studies revealed significantly enhanced immobilization efficiency of protein in comparison to RNA (data not shown). Following Lin28A immobilization, the wells were then incubated with pre-let-7d containing a 5 -trans-cyclooctene (TCO) click chemistry handle. Of note, this pre-let-7 isoform was chosen as its binding to $\operatorname{Lin} 28$ has been wellcharacterized. ${ }^{13}$ Importantly, binding of these modified substrates was successfully confirmed via an electrophoretic mobility shift assay (EMSA) (Figure S1A). Interaction of prelet-7d with Lin28A was detected via click chemistry with methyltetrazine-labeled horseradish peroxidase (mTet-HRP), followed by treatment with a HRP substrate and measurement of chemiluminescence signal. As shown in Figure S1B-D, the assay exhibited a $Z^{\prime}$ factor $^{32}$ of $>0.5$ using automated liquid handling, was dependent on the concentration of TCO-prelet-7d $\left(K_{\mathrm{d}, \text { app }}\right.$ of $\left.106 \mathrm{nM}\right)$, and was amenable to competition using unlabeled prelet-7d.
Encouraged by these promising results, we proceeded to HTS at the University of Michigan Center for Chemical Genomics. Our HTS assay protocol is summarized in Figure S2 and was performed using 384-well, high capacity, white streptavidin-coated well plates. In total, 127,007 small molecules were screened at $25 \mu \mathrm{M}$ from the LOPAC (1280), Prestwick (1280), Maybridge (23 552), ChemDiv (100 000), and University of Michigan Chemistry (895) libraries. The assay performed excellently with a campaign $Z^{\prime}$ factor of 0.5 and average plate $Z^{\prime}$ factor of 0.71 (Figure 1B). Using primary hit criteria of $\geq 25 \%$ inhibition, 1468 compounds were selected for triplicate analysis, yielding a hit rate of $1.1 \%$. Following hit confirmation, 181 molecules were selected that exhibited inhibition at $\geq 3$ SD by plate from the negative controls $(12 \%$ of hits). Compounds were then analyzed in dose response; 136 molecules ( $75 \%$ of confirmed hits) were active with inhibitory potencies ranging from $\mathrm{IC}_{50}$ of $0.01-100 \mu \mathrm{M} .^{33}$

After removing known promiscuous hits (i.e., PAINS) ${ }^{34}$ and filtering for reactivity issues and tractable medicinal chemistry scaffolds, 20 compounds were selected for repurchase (Figure S3). While 10 of the purchased compounds were found to retain activity (Figure S4), only two showed concentrationresponsive activity in both cat-ELCCA $\left(\mathrm{IC}_{50}\right.$ values of 8.3 and $10.3 \mu \mathrm{M}\left(n_{\mathrm{H}}=-1.3\right.$ and -1.2$)$, respectively) and EMSA: the $N, N^{\prime}$-(1,2-phenylene)-dibenzenesulfonamide derivatives CCG233094 and CCG-234459 (Figures 2 and S5). These compounds were also found to inhibit a cat-ELCCA of the pre-let-7d-Lin28B interaction with similar $\mathrm{IC}_{50}$ values (Figure S6). Additionally, they showed inhibition of the interaction between Lin28A and other pre-let-7 isoforms (Figure S7). Through additional analysis, the compounds were found to function through direct interaction with Lin28, as doseresponsive binding was only observed with the protein (Figure S8), not pre-let-7d (Figure S9). Importantly, these compounds showed insignificant inhibition of Dicer-mediated pre-let-7d maturation, in addition to a cat-ELCCA-based PPI assay 
A

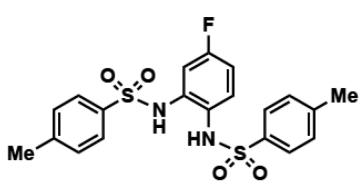

CCG-233094

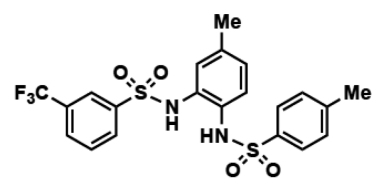

CCG-234459
B

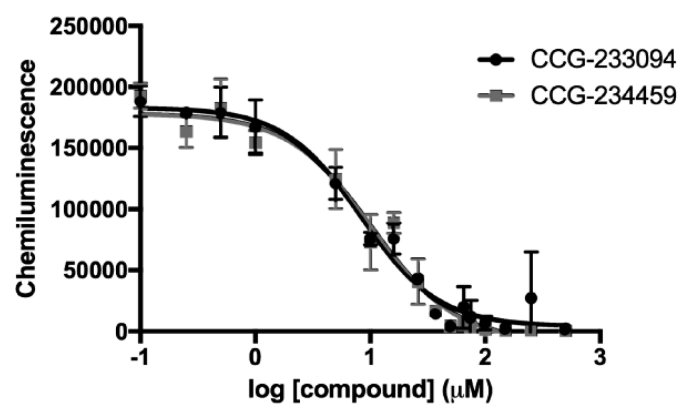

Figure 2. HTS hits for the pre-let-7d-Lin28A interaction. (A) Compound structures. (B) $\mathrm{IC}_{50}$ curves from 0-500 $\mu \mathrm{M}$.

(Figure S10), providing a promising selectivity profile for our hits.

In order to further profile this scaffold, we performed initial structure-activity relationship (SAR) studies by catalogue, and 18 derivatives were available for purchase from commercial vendors. While fluoro-substituted compounds, aside from CCG-233094, could not be obtained, 11 unsubstituted derivatives were tested. As shown in Table 1, all analogues were active, showing variable inhibitory potencies of 10-62 $\mu \mathrm{M}$. Several methyl-substituted analogues of CCG-234459 were also purchased and analyzed (Table 1). Again, each was active with $\mathrm{IC}_{50}$ values ranging between 11-28 $\mu \mathrm{M}$. Inhibition curves for both sets of compounds are shown in Figure S11.

Table 1. SAR by Catalogue of $N, N^{\prime}-(1,2-$ Phenylene)dibenzenesulfonamide Derivatives

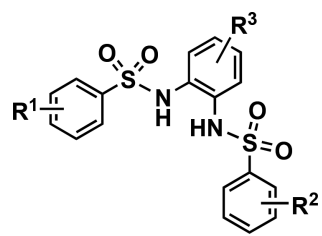

\begin{tabular}{|c|c|c|c|c|}
\hline compd & $\mathrm{R}^{1}$ & $\mathrm{R}^{2}$ & $\mathrm{R}^{3}$ & $\mathrm{IC}_{50}(\mu \mathrm{M})$ \\
\hline $1 \mathrm{a}$ & $\mathrm{H}$ & $\mathrm{H}$ & $\mathrm{H}$ & 32.2 \\
\hline $1 b$ & $p-\mathrm{F}$ & $\mathrm{H}$ & $\mathrm{H}$ & 13.9 \\
\hline $1 \mathrm{c}$ & $p-\mathrm{F}$ & $p-\mathrm{F}$ & $\mathrm{H}$ & 28.3 \\
\hline $1 d$ & $p$-F & $p-\mathrm{Cl}$ & $\mathrm{H}$ & 27.3 \\
\hline 1e & $p$-F & $p$-OMe & $\mathrm{H}$ & 17.2 \\
\hline If & $p$-F & $m-\mathrm{Cl}$ & $\mathrm{H}$ & 10.8 \\
\hline $1 \mathrm{~g}$ & $p-\mathrm{F}$ & $m-\mathrm{Br}$ & $\mathrm{H}$ & 16.2 \\
\hline $1 \mathrm{~h}$ & $p-\mathrm{Cl}$ & $p-\mathrm{Cl}$ & $\mathrm{H}$ & 27.5 \\
\hline $1 \mathrm{i}$ & $p-\mathrm{Br}$ & $p-\mathrm{Br}$ & $\mathrm{H}$ & 17.5 \\
\hline $\mathbf{1 j}$ & $p$-OMe & $p$-OMe & $\mathrm{H}$ & 16.7 \\
\hline $1 \mathrm{k}$ & $p$-NHCOMe & $p$-NHCOMe & $\mathrm{H}$ & 62.5 \\
\hline CCG-234459 & $m$-CF3 & $p$-Me & $\mathrm{Me}$ & 10.3 \\
\hline $2 \mathrm{a}$ & $\mathrm{H}$ & $\mathrm{H}$ & $\mathrm{Me}$ & 28.8 \\
\hline $2 b$ & $p-\mathrm{F}$ & $p-\mathrm{F}$ & $\mathrm{Me}$ & 16.2 \\
\hline $2 c$ & $p-\mathrm{F}$ & $p-\mathrm{Me}$ & $\mathrm{Me}$ & 11.7 \\
\hline $2 d$ & $p-\mathrm{Cl}$ & $p-\mathrm{Cl}$ & $\mathrm{Me}$ & 28.4 \\
\hline $2 e$ & $p-\mathrm{Me}$ & $p-\mathrm{Me}$ & $\mathrm{Me}$ & 14.1 \\
\hline
\end{tabular}

Although none of the compounds showed enhanced potency over the parent compounds, these studies revealed that a combination of a meta-electron-withdrawing group and parafluoro or -methyl substitution was optimal for maintaining inhibitory activity and that substituents on the center ring are not required. Additionally, two inactive molecules were identified: monosulfonamide 3 and $N, N^{\prime}$-(1,3-phenylene)dibenzenesulfonamide 4 (Figure 3 ), demonstrating the

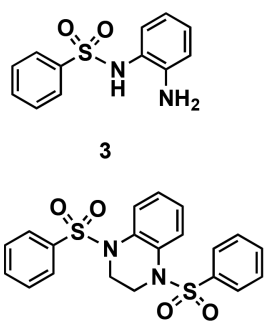

5

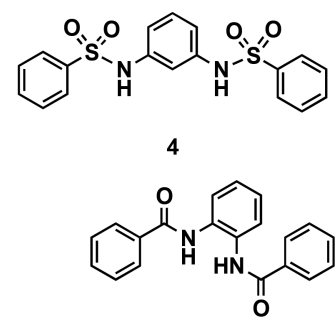

Figure 3. Structures of inactive scaffolds.

necessity of the bis-sulfonamide and its 1,2-orientation for activity. This was further emphasized through synthetic derivatives 5 and 6 (Figure 3), which were also found to be inactive.

To further probe the SAR of our discovered scaffold, additional derivatives were synthesized. Because the metachloro analogue If retained activity similar to that of our initial hits, we first examined if meta-substitution was tolerated on both rings. As shown in Table 2, the symmetric molecule 7a

Table 2. Additional SAR of $N, N^{\prime}-(1,2-$

Phenylene)dibenzenesulfonamide Derivatives

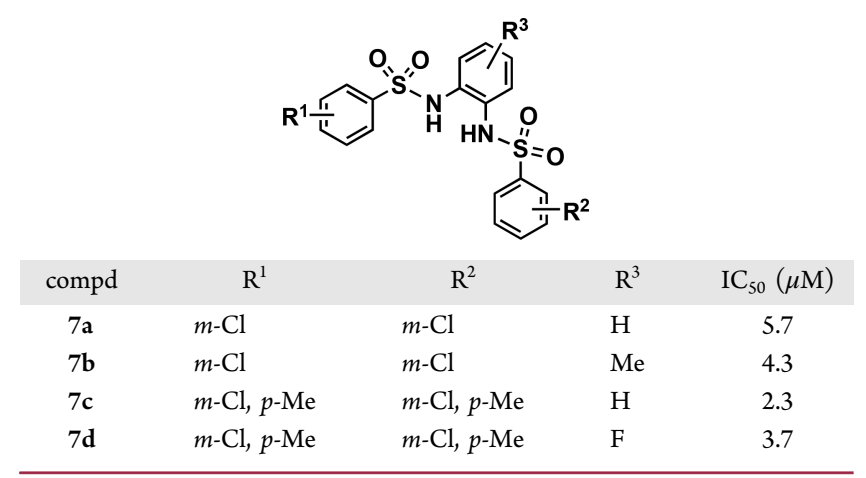

showed an improved $\mathrm{IC}_{50}$ value of $5.7 \mu \mathrm{M}$. Similar inhibitory activity was observed with the asymmetric methyl-substituted analogue $7 \mathbf{b}$. As our screening hits contained para-methyl substituents, we next explored its combination with a metachloro substituent. Importantly, compounds $7 \mathrm{c}$ and $7 \mathbf{d}$, containing unsubstituted or fluoro-substituted center rings, both showed further improvement in activity $\left(\mathrm{IC}_{50}\right.$ values of 2.3 and $3.7 \mu \mathrm{M}$, respectively). Thus, we are hopeful that this series can be further optimized through future efforts in structurebased drug design.

In conclusion, using the adaptability of cat-ELCCA, we have developed new assay technology for analyzing RNA-protein interactions. Using this approach, we subsequently performed HTS and identified a new class of inhibitor for the pre-let-7Lin28 interaction. ${ }^{35-37}$ As the important roles that RNAbinding proteins play in regulating RNA biology are emerging, ${ }^{38,39}$ there is a need for methods by which to discover 
small molecule chemical probes and drug leads for these targets. Similar to PPIs, RNA-protein interaction assays have relied on traditional methods such as fluorescence polarization, ${ }^{40}$ FRET, ${ }^{35,36}$ or AlphaScreen. ${ }^{41}$ Although useful for high-throughput experimentation, these assays can be limited by size requirements and the need for structural information for assay design. Because cat-ELCCA is amenable to HTS, utilizes a simple $\mathrm{N}$ - or $\mathrm{C}$-terminus protein modification strategy, and does not require structural information, it should be an enabling tool for these future research endeavors. While there are many benefits to this new technology, limitations include the need for washing steps, which can hinder throughput and restrain its use to interactions with binding affinities $\leq 1.0 \mu \mathrm{M}$, similar to ELISA. Efforts are currently underway to engineer cat-ELCCA as a homogeneous chemiluminescence-based assay.

\section{ASSOCIATED CONTENT}

\section{S Supporting Information}

The Supporting Information is available free of charge on the ACS Publications website at DOI: 10.1021/acsmedchemlett.8b00126.

General synthetic, protein expression/purification, and bioconjugation methods, protocol for pre-let-7-Lin28 cat-ELCCA, HTS details, supplemental figures, 95\% confidence intervals for measured $\mathrm{IC}_{50}$ values, and compound characterization and purity spectra (PDF)

\section{AUTHOR INFORMATION}

\section{Corresponding Author}

*E-mail: algarner@umich.edu.

\section{ORCID $\odot$}

Amanda L. Garner: 0000-0002-0870-3347

\section{Author Contributions}

The manuscript was written through contributions of D.A.L., T.K., and A.L.G. All authors have given approval to the final version of the manuscript.

\section{Funding}

This work was supported through a Catalyst Award from the Dr. Ralph and Marian Falk Medical Research Trust.

\section{Notes}

The authors declare no competing financial interest.

\section{Biography}

Amanda Garner received her Ph.D. in Chemistry from the University of Pittsburgh working under the supervision of Prof. Kazunori Koide and completed NIH-funded postdoctoral studies in the laboratory of Prof. Kim Janda at The Scripps Research Institute. She began her independent career in 2013 in the Department of Medicinal Chemistry at the University of Michigan. Her laboratory uses chemical biology, medicinal chemistry, and molecular and cellular biology approaches to investigate the high-risk/high-reward areas of targeting microRNAs and RNA-protein and protein-protein interactions for probe and drug discovery.

\section{ACKNOWLEDGMENTS}

We thank Martha Larsen and Steve Vander Roest for assistance with the HTS. We also thank Glory Velazquez for assistance in preparing Lin28B.

\section{ABBREVIATIONS}

miRNA or miR, microRNA; miR-BP, microRNA-binding protein; HTS, high-throughput screening; cat-ELCCA, catalytic enzyme-linked click chemistry assay; TCO, trans-cyclooctene; mTet, methyltetrazine; HRP, horseradish peroxidase; $n_{\mathrm{H}}$, Hill slope; EMSA, electrophoretic mobility shift assay; SD, standard deviation; SAR, structure-activity relationship

\section{REFERENCES}

(1) Li, Z.; Rana, T. M. Therapeutic targeting of microRNAs: current status and future challenges. Nat. Rev. Drug Discovery 2014, 13, 622638.

(2) Garzon, R.; Marcucci, G.; Croce, C. M. Targeting microRNAs in cancer: rationale, strategies and challenges. Nat. Rev. Drug Discovery 2010, 9, 775-789.

(3) Ling, H.; Fabbri, M.; Calin, G. A. MicroRNAs and other noncoding RNAs as targets for anticancer drug development. Nat. Rev. Drug Discovery 2013, 12, 847-865.

(4) Rupaimoole, R.; Slack, F. J. MicroRNA therapeutics: towards a new era for the management of cancer and other diseases. Nat. Rev. Drug Discovery 2017, 16, 203-221.

(5) van Kouwenhove, M.; Kedde, M.; Agami, R. MicroRNA regulation by RNA-binding proteins and its implications in cancer. Nat. Rev. Cancer 2011, 11, 644-656.

(6) Thomson, J. M.; Newman, M. A.; Parker, J. S.; Morin-Kensicki, E. M.; Wright, T.; Hammond, S. M. Extensive post-transcriptional regulation of microRNAs and its implications for cancer. Genes Dev. 2006, 20, 2202-2207.

(7) Kumar, M. S.; Lu, J.; Mercer, K. L.; Golub, T. R.; Jacks, T. Impaired microRNA processing enhances cellular transformation and tumorigenesis. Nat. Genet. 2007, 39, 673-677.

(8) Lee, E. J.; Baek, M.; Gusev, Y.; Brackett, D. J.; Nuovo, G. J.; Schmittgen, T. D. Systematic evaluation of microRNA processing patterns in tissues, cell lines, and tumors. RNA 2008, 14, 35-42.

(9) Ha, M.; Kim, V. N. Regulation of microRNA biogenesis. Nat. Rev. Mol. Cell Biol. 2014, 15, 509-524.

(10) Viswanathan, S. R.; Daley, G. Q.; Gregory, R. I. Selective blockade of microRNA processing by Lin28. Science 2008, 320, 97100.

(11) Newman, M. A.; Thomson, J. M.; Hammond, S. M. Lin-28 interaction with the let-7 precursor loop mediates regulated microRNA processing. RNA 2008, 14, 1539-1549.

(12) Lin, S.; Gregory, R. I. MicroRNA biogenesis pathways in cancer. Nat. Rev. Cancer 2015, 15, 321-333.

(13) Nam, Y.; Chen, C.; Gregory, R. I.; Chou, J. J.; Sliz, P. Molecular basis for interaction of let-7 microRNAs with Lin28. Cell 2011, 147, 1080-1091.

(14) Loughlin, F. E.; Gebert, L. F. R.; Towbin, H.; Brunschweiger, A.; Hall, J.; Allain, F. H.-T. Structural basis of pre-let-7 miRNA recognition by the zinc knuckles of pluripotency factor Lin28. Nat. Struct. Mol. Biol. 2012, 19, 84-89.

(15) Wang, L.; Nam, Y.; Lee, A. K.; Yu, C.; Roth, K.; Chen, C.; Ransey, E. M.; Sliz, P. LIN28 zinc knuckle domain is required and sufficient to induce let-7 oligouridylation. Cell Rep. 2017, 17, 26642675.

(16) Roush, S.; Slack, F. J. The let-7 family of microRNAs. Trends Cell Biol. 2008, 18, 505-516.

(17) Heo, I.; Joo, C.; Cho, J.; Ha, M.; Han, J.; Kim, V. N. Lin28 mediates the terminal uridylation of let-7 precursor microRNA. Mol. Cell 2008, 32, 276-284.

(18) Viswanathan, S. R.; Powers, J. T.; Einhorn, W.; Hoshida, Y.; Ng, T. L.; Toffanin, S.; O’Sullivan, M.; Lu, J.; Phillips, L. A.; Lockhart, V. L.; Shah, S. P.; Tanwar, P. S.; Mermel, C. H.; Beroukhim, R.; Azam, M.; Teixeira, J.; Meyerson, M.; Hughes, T. P.; Llovet, J. M.; Radich, J.; Mullighan, C. G.; Golub, T. R.; Sorensen, P. H.; Daley, G. Q. Lin28 promotes transformation and is associated with advanced human malignancies. Nat. Genet. 2009, 41, 843-848. 
(19) Esquela-Kerscher, A.; Trang, P.; Wiggins, J. F.; Patrawala, L.; Cheng, A.; Ford, L.; Weidhaas, J. B.; Brown, D.; Bader, A. G.; Slack, F. $\mathrm{J}$. The let-7 microRNA reduces tumor growth in mouse models of lung cancer. Cell Cycle 2008, 7, 759-764.

(20) Kumar, M. S.; Erkeland, S. J.; Pester, R. E.; Chen, C. Y.; Ebert, M. S.; Sharp, P. A.; Jacks, T. Suppression of non-small cell lung tumor development by the let-7 microRNA family. Proc. Natl. Acad. Sci. U. S. A. 2008, 105, 3903-3908.

(21) Nguyen, L. H.; Robinton, D. A.; Seligson, M. T.; Wu, L.; Li, L.; Rakheja, D.; Comerford, S. A.; Ramezani, S.; Sun, X.; Parikh, M. S.; Yang, E. H.; Powers, J. T.; Shinoda, G.; Shah, S. P.; Hammer, R. E.; Daley, G. Q.; Zhu, H. Lin28b is sufficient to drive liver cancer and necessary for its maintenance in murine models. Cancer Cell 2014, 26, 248-261.

(22) Molenaar, J. J.; Domingo-Fernandez, R.; Ebus, M. E.; Lindner, S.; Koster, J.; Drabek, K.; Mestdagh, P.; van Sluis, P.; Valentijn, L. J.; van Nes, J.; Broekmans, M.; Haneveld, F.; Volckmann, R.; Bray, I.; Heukamp, L.; Sprussel, A.; Thor, T.; Kieckbusch, K.; Klein-Hitpass, L.; Fischer, M.; Vandesompele, J.; Schramm, A.; van Noesel, M. M.; Varesio, L.; Speleman, F.; Eggert, A.; Stallings, R. L.; Caron, H. N.; Versteeg, R; Schulte, J. H. LIN28B induces neuroblastoma and enhances MYCN levels via let-7 suppression. Nat. Genet. 2012, 44, 1199-1206.

(23) Hamano, R.; Miyata, H.; Yamasaki, M.; Sugimura, K.; Tanaka, K.; Kurokawa, Y.; Nakajima, K.; Takiguchi, S.; Fujiwara, Y.; Mori, M.; Doki, Y. High expression of Lin28 is associated with tumour aggressiveness and poor prognosis of patients with oesophagus cancer. Br. J. Cancer 2012, 106, 1415-1423.

(24) Garner, A. L.; Janda, K. D. cat-ELCCA: a robust method to monitor the fatty acid acyltransferase activity of ghrelin $\mathrm{O}$ acyltransferase(GOAT). Angew. Chem., Int. Ed. 2010, 49, 9630-9634. (25) Lorenz, D. A.; Song, J. M.; Garner, A. L. High-throughput platform assay technology for the discovery of pre-microRNA-selective small molecule probes. Bioconjugate Chem. 2015, 26, 19-23.

(26) Lorenz, D. A.; Garner, A. L. A click chemistry-based microRNA maturation assay optimized for high-throughput screening. Chem. Commun. 2016, 52, 8267-8270.

(27) Garner, A. L. cat-ELCCA: catalyzing drug discovery through click chemistry. Chem. Commun. 2018, DOI: 10.1039/C8CC02332H.

(28) Lorenz, D. A.; Garner, A. L. Approaches for the discovery of small molecule ligands targeting microRNAs. Top. Med. Chem. 2017, $27,79-110$.

(29) Lorenz, D. A.; Vander Roest, S.; Larsen, M. J.; Garner, A. L. Development and implementation of an HTS-compatible assay for the discovery of selective small-molecule ligands for pre-microRNAs. SLAS Disc. 2018, 23, 47-54.

(30) Garner, A. L.; Janda, K. D. A small molecule antagonist of ghrelin O-acyltransferase(GOAT). Chem. Commun. 2011, 47, 75127514 .

(31) Song, J. M.; Menon, A.; Mitchell, D. C.; Johnson, O. T.; Garner, A. L. High-throughput chemical probing of full-length protein-protein interactions. ACS Comb. Sci. 2017, 19, 763-769.

(32) Zhang, J.-H.; Chung, T. D. Y.; Oldenburg, K. R. A simple statistical parameter for use in evaluation and validation of high throughput screening assays. J. Biomol. Screening 1999, 4, 67-73.

(33) Of note, the compound displaying a $10 \mathrm{nM} \mathrm{IC}_{50}$ value from our HTS contained a tetrazine that was found to react with our TCOlabeled prelet-7d (Figure S3).

(34) Baell, J. B.; Holloway, G. A. New substructure filters for removal of pan assay interference compounds(PAINS) from screening libraries and for their exclusion in bioassays. J. Med. Chem. 2010, 53, 27192740.

(35) Roos, M.; Pradere, U.; Ngondo, R. P.; Behera, A.; Allegrini, S.; Civenni, G.; Zagalak, J. A.; Marchand, J.-R.; Menzi, M.; Towbin, H.; Scheuermann, J.; Neri, D.; Caflisch, A.; Catapano, C. V.; Claudo, C.; Hall, J. A small-molecule inhibitor of Lin28. ACS Chem. Biol. 2016, 11, 2773-2781.

(36) Lim, D.; Byun, W. G.; Koo, J. Y.; Park, H.; Park, S. B. Discovery of a small-molecule inhibitor of protein-microRNA interaction using binding assay with a site-specifically labeled Lin28. J. Am. Chem. Soc 2016, 138, 13630-13638.

(37) Lightfoot, H. L.; Miska, E. A.; Balasubramanian, S. Identification of small molecule inhibitors of the Lin28-mediated blockage of pre-let$7 \mathrm{~g}$ processing. Org. Biomol. Chem. 2016, 14, 10208-10216.

(38) Gerstberger, S.; Hafner, M.; Tuschl, T. A census of human RNA-binding proteins. Nat. Rev. Genet. 2014, 15, 829-845.

(39) Hentze, M. W.; Castello, A.; Schwarzl, T.; Preiss, T. A brave new world of RNA-binding proteins. Nat. Rev. Mol. Cell Biol. 2018, 19, 327.

(40) Wu, X.; Lan, L.; Wilson, D. M.; Marquez, R. T.; Tsao, W.-C.; Gao, P.; Roy, A.; Turner, B. A.; McDonald, P.; Tunge, J. A.; Rogers, S. A.; Dixon, D. A.; Aube, J.; Xu, L. Identification and validation of novel small molecule disruptors of HuR-mRNA interaction. ACS Chem. Biol. 2015, 10, 1476-1484.

(41) Mills, N. L.; Shelat, A. A.; Guy, R. K. Assay optimization and screening of RNA-protein interactions by AlphaScreen. J. Biomol. Screening 2007, 12, 946-955. 